\title{
Endocrinological and Histological Aspects of the Process of Polycystic Ovary Formation in the Rat Treated with Testosterone Propionate
}

\author{
Hirotaka Ota, Mineko Fukushima and Masahiro Maki \\ Department of Obstetrics and Gynecology, Akita University \\ School of Medicine, Akita 010
}

\begin{abstract}
Ota, H., Funushima, M. and MaKi, M. Endocrinological and Histological Aspects of the Process of Polycystic Ovary Formation in the Rat Treated with Testosterone Propionate. Tohoku J. exp. Med., 1983, 140 (2), 121-131 — To elucidate the process underlying polycystic ovary (PCO) syndrome, we tried to produce experimental PCO by sterilizing rats with androgen and investigated the formation of PCO endocrinologically and histologically. Wistar-Imamichi strain female rats were given an injection of testosterone propionate $1.25 \mathrm{mg}$ on 5 days of age. On $5,10,20,40,60,80,100,130,160,200$ days after the injection the ovaries were obtained. Ovarian wedge resection was also performed at 100 and 200 day-rats. Serum gonadotropins, prolactin and steroids were measured with RIA and compared with ovarian pathology. Serum prolactin was increased drastically 40 days after the injection and maintained at a constant level higher than control. Through wedge resection, the serum LH level returned to normal, but FSH slightly increased. Serum estradiol decreased more markedly than estrone did. The 40 day-ovaries showed polycystic features, lack of corpus luteum, hyperthecosis, luteinization of stroma, while no thickening of tunica albuginea. In conclusion, the rats treated with testosterone propionate had many endocrinological and histological aspects similar to those of human PCO syndrome.

experimental polycystic ovary; testosterone-induced rat; hyperprolactinemia
\end{abstract}

Endocrinological features of polycystic ovary (PCO) syndrome are characterized by high levels of serum LH and testosterone, high estrone to estradiol ratios (Rajaniemi et al. 1980; Quigley et al. 1981), and by excessive response of the serum LH level to LH-RH stimulation (Duignan 1976; Ota et al. 1979). About thirty percent of the patients are associated with hyperprolactinemia (Thorner 1977; Ota et al. 1979; Alger et al. 1980; Wortsman and Hirschowitz 1980). In half of the patients clomiphene citrate is ineffective. Some of them are sensitive to gonadotropin therapy and tend to cause ovarian hyperstimulation syndrome (Fukushima et al. 1980).

Ovarian wedge resection (WR) is often applied to the cases insensitive to pharmacological treatment, resulting in frequent induction of ovulation. Its mechanism, however, is poorly understood.

Received for publication, September 6, 1982.

Reprint address: Hirotaka Ota, Department of Obstetrics and Gynecology, Akita University School of Medicine, 1-1-1 Hondo, Akita 010, Japan. 
In this paper we experimentally produced PCO, treated it with testosterone propionate (TP), and investigated endocrinologically and microscopically the process of the formation of PCO and changes after WR.

\section{Materials and Methods}

\section{Experimental animals}

Wistar-Imamichi strain female rats aged 5 days were obtained from Imamichi Institute for Animal Reproduction. They were kept under a $14 \mathrm{hr}$ light and $10 \mathrm{hr}$ dark condition at a constant temperature of $21^{\circ} \mathrm{C}$. Purina laboratory chow (CE-2, CELA Co., Ltd.) and water were provided freely throughout the period of experiment.

The female 5-day-old rats were given a single subcutaneous injection of $1.25 \mathrm{mg}$ of TP in $0.2 \mathrm{ml}$ sesame oil. They were kept together with their mothers until weaning. Control groups received injections of $0.2 \mathrm{ml}$ sesame oil alone.

On $5,10,20,40,60,80,100,130,160$ and 200 days after the injection blood samples were obtained from the jugular vein and the ovaries were excised under ether anesthesia. The sərum samples were stored at $-20^{\circ} \mathrm{C}$ until the time of assay. Vaginal smears were checked throughout the experimental period after vaginal opening. The control group showed vaginal smears of diestrus.

Ovarian wedge resection was performed by laparotomy on 100 and 200 days after the TP injection and the animals were autopsied 24 or $48 \mathrm{hr}$ after the operation.

\section{Tissue preparation}

Both ovaries excised were fixed in $10 \%$ neutral formalin, serially sectioned at $2 \mu \mathrm{m}$ and stained with hematoxylin and eosin.

Hormone assay

Serum LH, FSH and prolactin were quantified by the double antibody radioimmunoassay (RIA) technique, using the antibody obtained through the rat distribution program of the National Institute of Arthritis, Metabolism and Digestive Diseases.

Serum estradiol was measured, using the kit from CIS, Co., Ltd. and the technique of

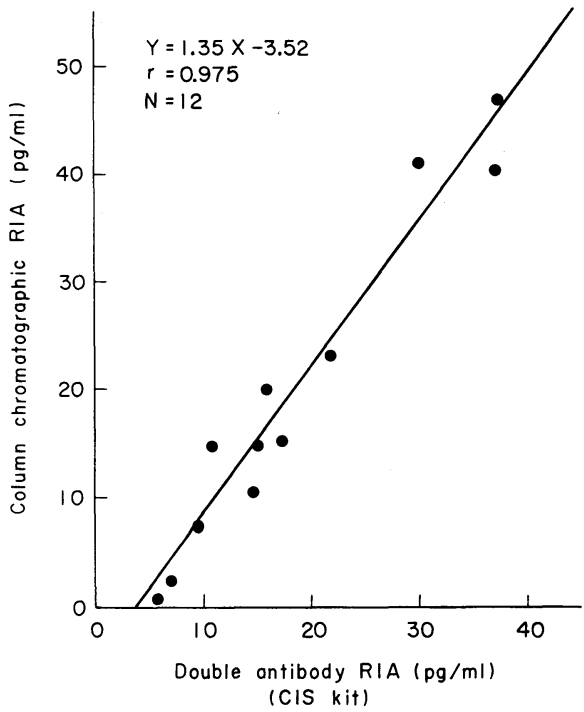

Fig. 1. Comparison of serum estradiol values obtained by column chromatographic and double antibody radioimmunoassay methods. 
column chromatographic RIA by Makino-Kanbegawa's method (Kanbegawa 1975). Correlation between the two methods of serum estrogen determination was highly significant, as shown in Fig. 1. Serum testosterone was estimated by the double antibody technique from Eiken, Co., Ltd.
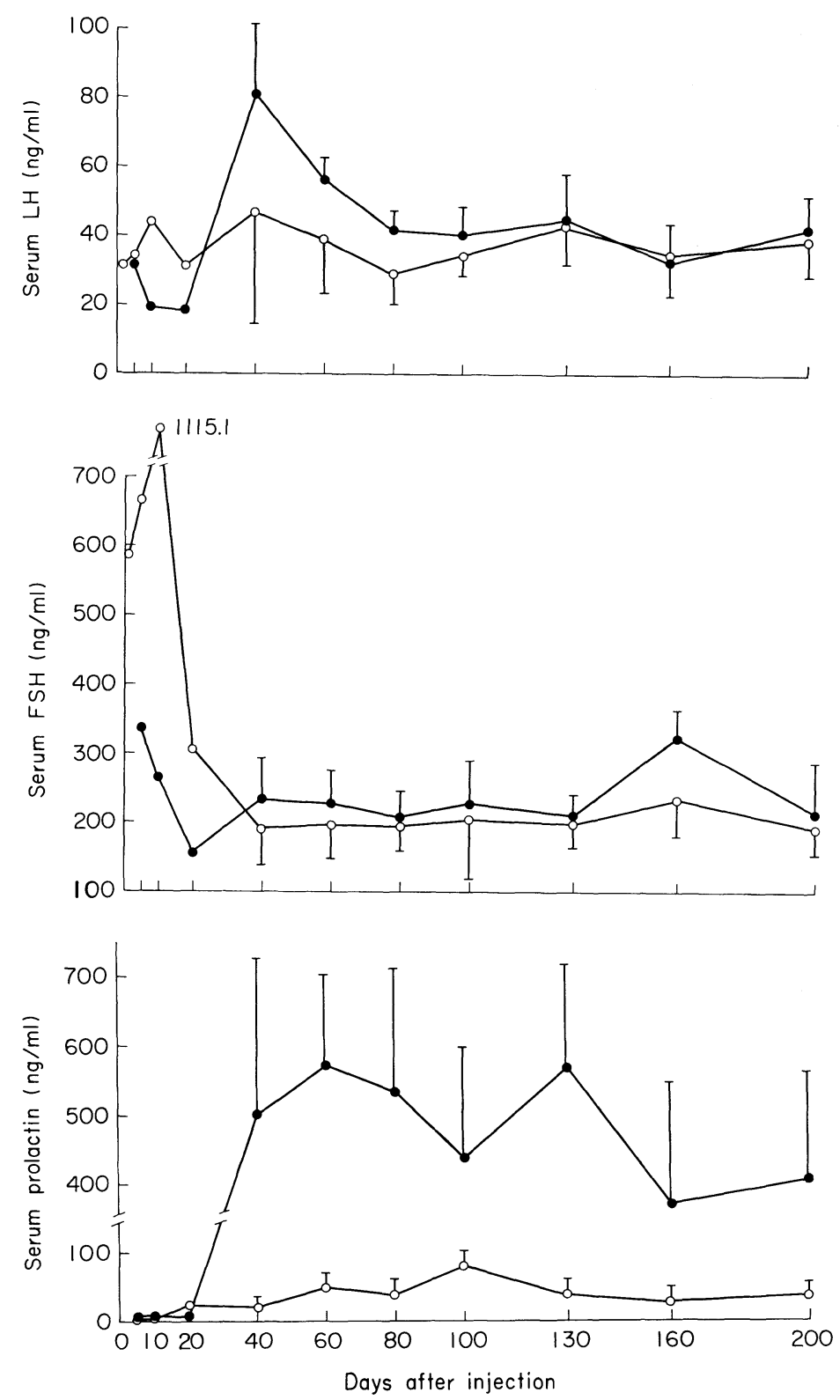

Fig. 2. Changes of serum LH, FSH and prolactin levels in the rats treated with sesame oil

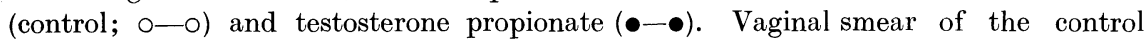
rats showed the diestrus stage. Each point and bar show mean \pm s.D. of five to seven animals. 


\section{Statistical Analysis}

Results were expressed as means \pm s.D. The significance of differences was examined by Student's $t$-test.

\section{Results}

\section{Change of serum LH, FSH and prolactin after TP administration}

On 10 and 20 days after TP injection, the serum LH level was lower than control, but it was elevated drastically on 40 days and then was maintained at a level slightly higher than control till 100 days.

The serum FSH level was also lower than control on 5, 10 and 20 days, and was kept at a higher level from 40 days after the injection.

Serum prolactin levels in both TP-administered and control groups were low till 10 days. A marked increase was observed on 40 days after treatment with TP and the high level was maintained thereafter (Fig. 2). Thus, the serum LH increased coincidentally with prolactin on 40 days after the TP administration.
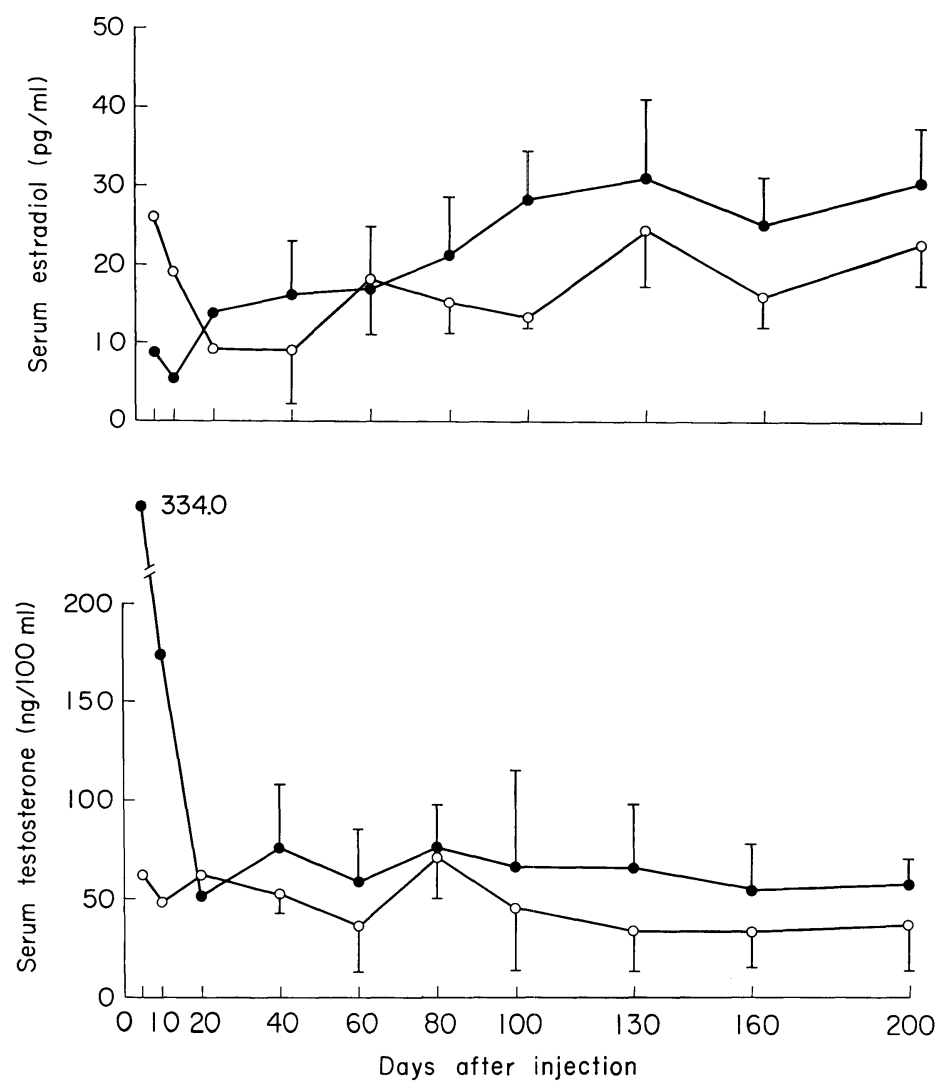

Fig. 3. Changes of serum estradiol and testosterone levels in the rats treated with sesame oil (control; ○trol rats showed the diestrus stage. Each point and bar show mean \pm s.D. of five to seven animals. 
Changes of serum estradiol and testosterone after TP administration

In the control group a physiological increase of estradiol was observed on 5 and 10 days after TP administration, while the serum estradiol level was low in the TP-treated rats. On 20 days the serum estradiol level of the TP-treated rats exceeded that of the control rats and remained at a constant high level thereafter.

On 5 and 10 days serum testosterone in the treated rats exhibited a high level, and was maintained higher than the control level thereafter, suggesting excessive production from the ovary (Fig. 3).

Changes of serum LH, FSH, prolactin, estradiol and testosterone levels before and after ovarian $W R$

Ovarian WR was performed on 100 or 200 days after TP injection.

The serum LH level reduced significantly $(p<0.01) 24$ and $48 \mathrm{hr}$ after WR in either group.
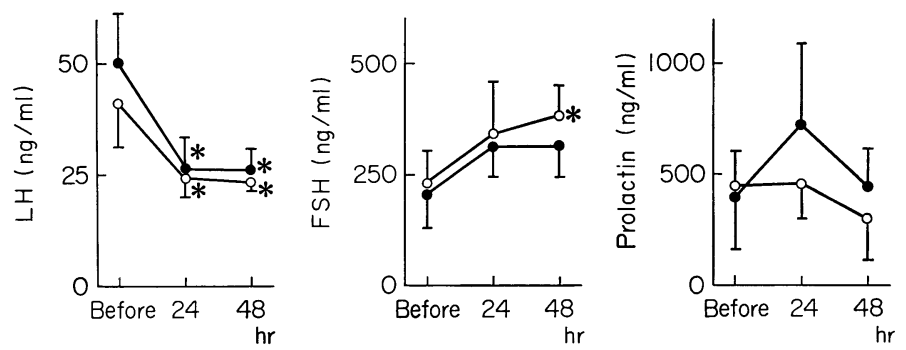

Fig. 4. Changes of serum LH, FSH and prolactin levels before and after WR. Open (०-०) and closed (-๑) circles show the resection performed on 100 days and 200 days after treatment with testosterone propionate. Each point and bar show mean \pm s.D. of four to five animals. * Significantly different from the values before WR.
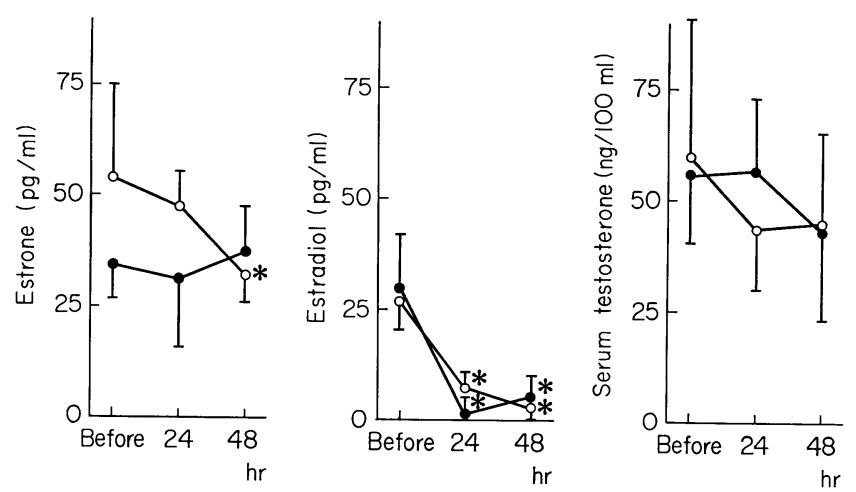

Fig. 5. Changes of serum testosterone and estrogen levels before and after WR. Open

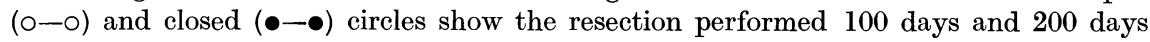
after treatment with testosterone propionate. Each point and bar show mean \pm s.D. of four to five animals. * Significantly different from the values before WR. 
The serum FSH level showed a significant increase $(p<0.01) 48 \mathrm{hr}$ after the operation performed on 100 days after TP administration, while it was not changed significantly when the WR was performed on 200 days.

The serum prolactin level showed no distinct changes after operation (Fig. 4).

The serum estrone level was reduced significantly $(p<0.05)$ after WR on 100

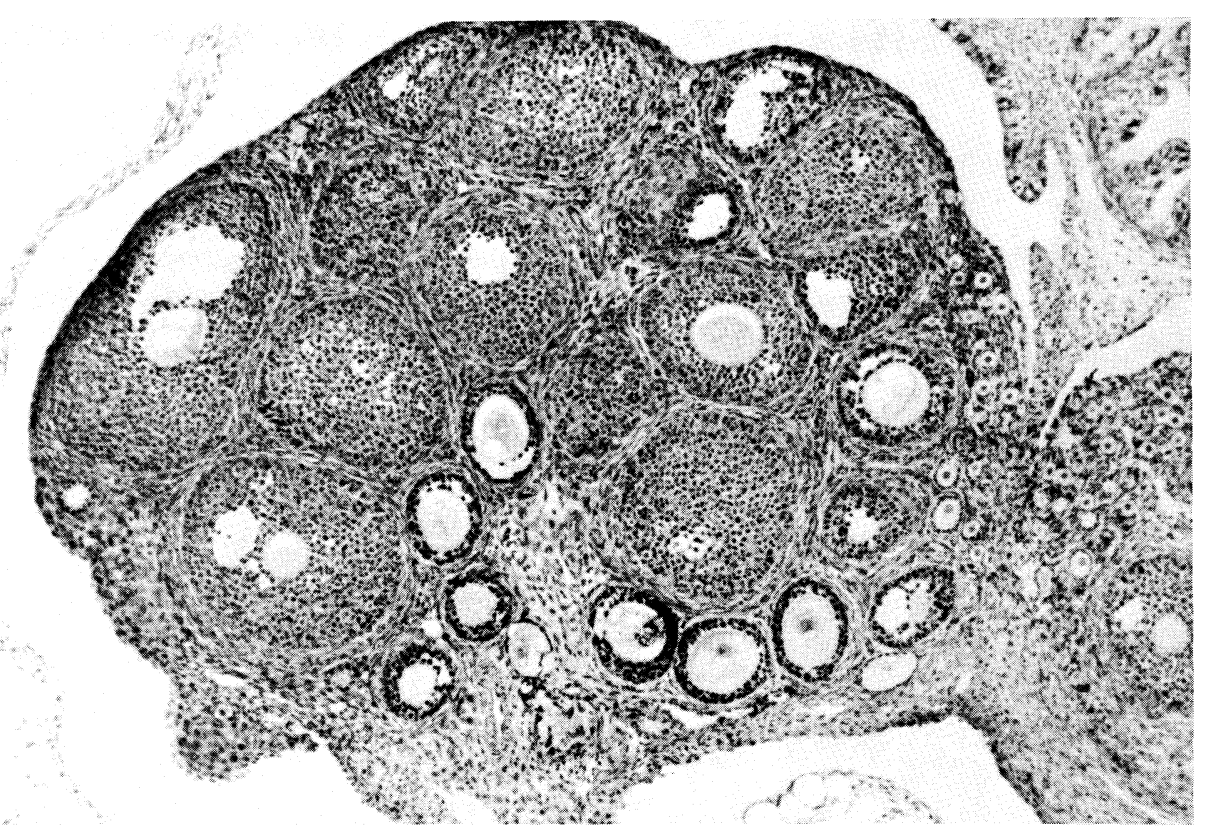

Fig. 6. An ovarian section from the rat on 20 days after treatment with $0.2 \mathrm{ml}$ sesame oil.

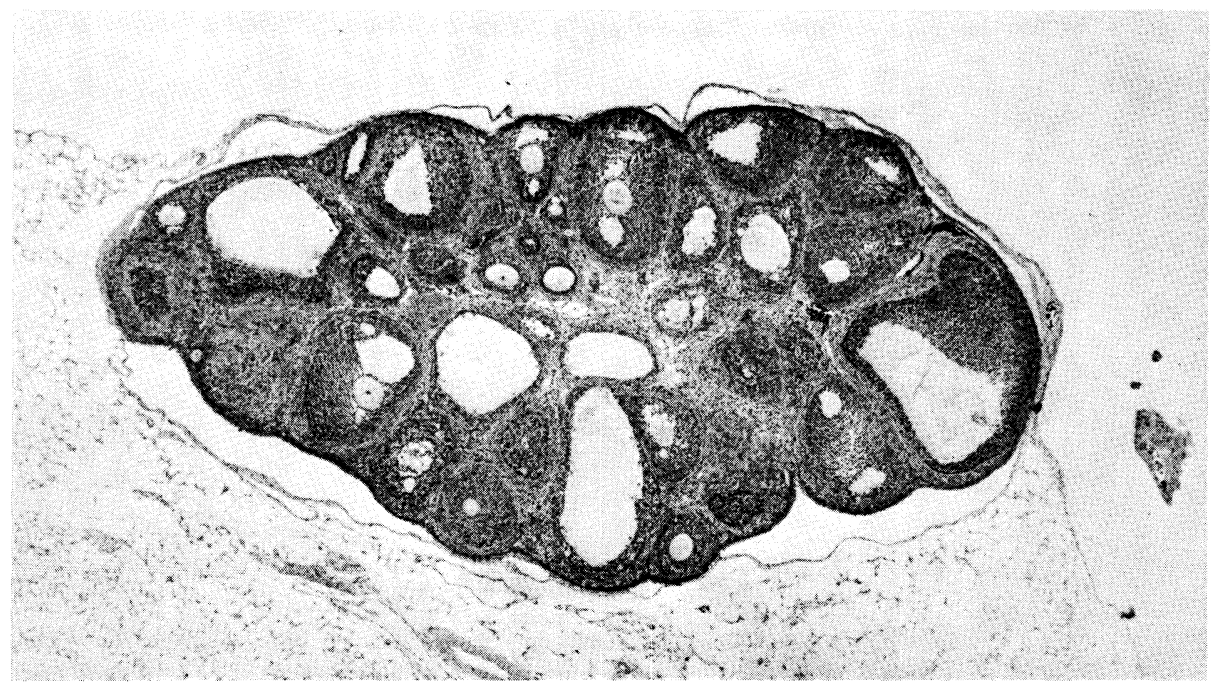

Fig. 7. An ovarian section showing cystic and atretic follicles and hyperthecosis in a rat 20 days after treatment with testosterone propionate. 


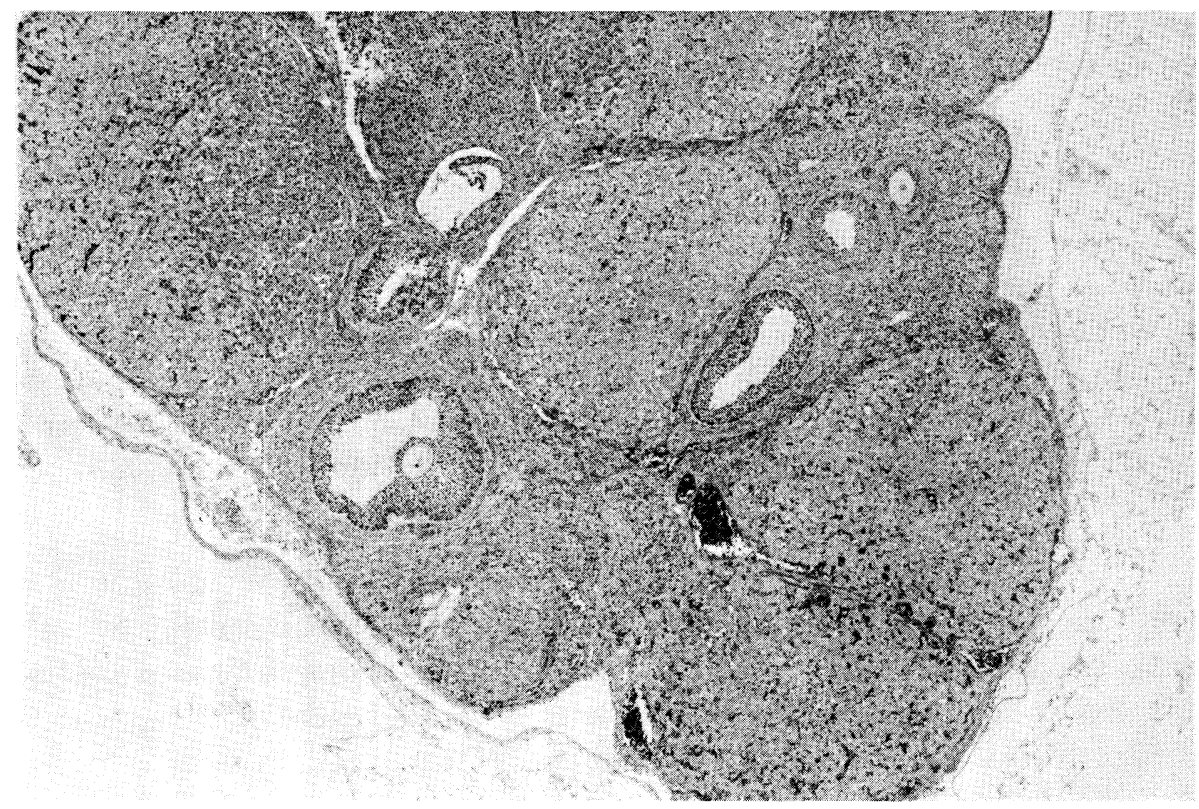

Fig. 8. An ovarian section from the rat at the diestrus stage 40 days after treatment with $0.2 \mathrm{ml}$ sesame oil.

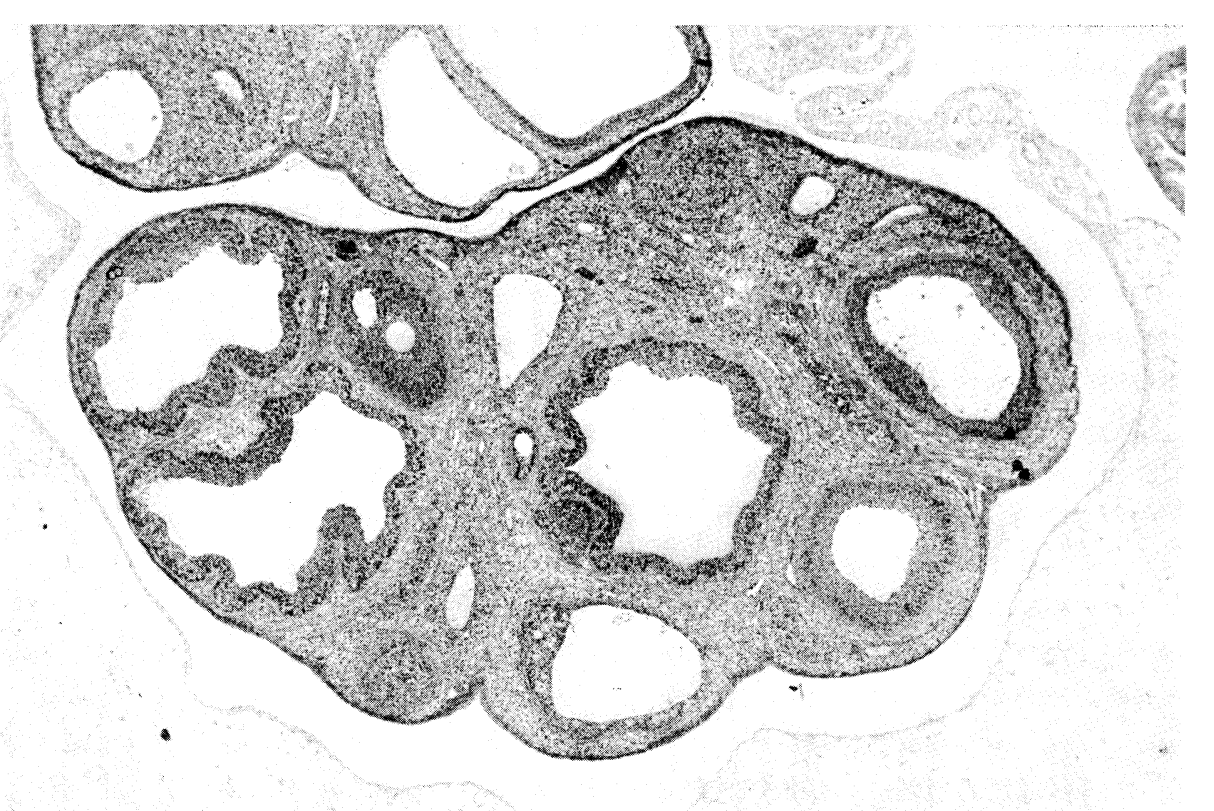

Fig. 9. An ovarian section showing polycystic follicles and luteinization of stroma and theca cells in the rat 40 days after treatment with testosterone propionate. 
days after TP administration, but it remained almost unchanged after WR on 200 days. On the contrary, serum estradiol decreased significantly even after resection on 200 days $(p<0.001)$. The serum testosterone level also decreased slightly after WR (Fig. 5).

\section{Ovarian histology}

An ovarian section from the control rat on 20 days of experiment contained follicles in various stages of development (Fig. 6). On the other hand, one from the treated rat showed cystic formation, atretic follicles and luteinization of theca cells (Fig. 7). On 40 days multiple cystic formation and hyperthecosis were observed in the treated rats, but no thickening of tunica albuginea nor corpora lutea (Figs. 8, 9). Even after WR, no corpora lutea were seen.

\section{Discussion}

Cystic formation in the rat ovary can be induced experimentally by various methods; postnatal treatment with hormones, such as androgen (Mazer and Mazer 1939; Shay et al. 1939; Bradbury 1941; Barraclough 1961; Black and Mahesh 1969), estrogen (Gorski 1963) and hCG (Greene and Burrill 1941), hypothalamic lesions (Halász and Pupp 1965) and exposure of adult rats to continuous light (Maric et al. 1965). In this paper we induced successfully the experimental polycystic ovary in androgen sterilized rats by the methods of Barraclough (1961), and investigated endocrinologically and microscopically the process of its formation.

Endocrinological features of the experimentally induced PCO in rats treated with TP were similar to those of human polycystic ovary syndrome. Serum LH was low 5, 10 and 20 days after TP injection and increased markedly on 40 days without ovulation, which was accompanied with an increase of serum prolactin. Knudsen et al. (1975) and Ward et al. (1978), on the other hand, reported that rats treated with dehydroepiandrosterone presented rather low levels of LH. This implies that in the TP-treated rats, tonic secretion of $\mathrm{LH}$ from the anterior pituitary is well maintained without cyclic secretion.

In the control group serum FSH showed a physiological increase on 5, 10 and 20 days of experiment. This period is considered to be important for ovarian follicle maturation (Odell and Swerdloff 1976). In the TP-treated rats, the level of FSH was rather low till 40 days and became higher than the control level thereafter. This FSH secretion pattern is different from that in human PCO syndrome which shows a level lower than normal. This discrepancy seems to be due to different levels of estradiol or ratio of estrone to estradiol. Saito and Fukushima (1969) proved that some dosis of ethinylestradiol stimulates FSH secretion and that conjugated equine estrogen which mainly consists of estrone stimulates LH, but not FSH secretion in human beings. So, in the TP-treated rats estradiol may stimulate FSH secretion, while in human PCO syndrome dominant estrone possibly stimulates only LH secretion.

Serum prolactin concentration increased drastically on 40 days and then 
remained at a high level until 200 days. This result seems interesting, because serum prolactin is essential for ovulation and acts on corpus luteum as a luteotropic (Holt et al. 1976) or luteolytic (Huang and Pearlman 1962) agent in the rat, while some of human PCO patients with hyperprolactinemia are more resistent to clomiphene therapy and some are more sensitive to gonadotropin therapy, resulting in ovarian hyperstimulation syndrome. This high level of prolactin in the rat can be also induced by treatment with dehydroepiandrosterone (Kundsen et al. 1975; Ward et al. 1978) or hypophyseal transplantation (Nikitovitch-Winer 1965). Two hypotheses are to be considered as the reasons. One is that the high estradiol level in the TP-treated rats may act on the pituitary and induce prolactin secretion, as Thorner (1977) reported. The other is that the dopaminergic control of prolactin secretion is disturbed in PCO patients, which leads to hyperprolactinemia, as Alger et al. (1980) proved the excessive response of serum prolactin by the administration of metoclopramide, a dopamine receptor antagonist.

The serum estradiol level was low on 5 and 10 days after TP treatment, probably because of low gonadotropin secretion, and came to be high 20 days later, corresponding closely with ovarian cystic formation, hyperthecosis and luteinization of the theca cells. The estrone level was rather low, as compared with estradiol level, which indicates the discrepancy between human and rat PCO.

Serum testosterone concentration was higher than the control, which was found similarly in the human PCO syndrome and suggested the excessive production in the rat ovary.

After ovarian WR on 100 or 200 days after TP administration, serum LH returned to normal. The reduction of serum LH may be due partly to the stress stimulating prolactin secretion and partly to the decreased testosterone level as the results of positive feedback control. Serum FSH increased after WR, suggesting the feedback mechanism of estradiol. Serum estrone was slightly decreased, while the estradiol was markedly decreased. In human PCO syndrome, the serum LH level after WR was reported to be normalized (Valkov and Dokumov 1977; Katz et al. 1978) or not changed (Judd et al. 1976). FSH was also reported to remain unchanged. The mechanism of ovulation after WR is not completely understood. There are several hypotheses, one of which mentioned that the anovulation of polycystic ovary would be rather mechanical, as after snipping a part of the thickened ovarian capsule, ovulation can easily occur. Secondly, the decrease in ovarian steroids may allow the ovary to alter the process of steroidogenesis, which increases ovarian sensitivity and adequate follicular growth, leading to subsequent ovulation.

Microscopically, the ovary on 20 days after TP injection showed a cystic degeneration of follicles and luteinization of theca cells. On 40 days, the formation of polycystic ovary and hyperthecosis occurred, while there was neither thickening of tunica albuginea nor corpora lutea. The luteinization of thecal layer was more marked in the experimental rats than in human PCO syndrome, resulting in sufficient secretion of estradiol or testosterone. 
In conclusion, the rat ovaries on 40 days after TP administration showed the endocrinological and histological findings and features almost similar to those of human PCO syndrome.

\section{Acknowledgment}

We obtained testosterone propionate through the courtesy of Dr. A. Kanbegawa, Teikokuzoki Co., Ltd., Tokyo, and r-LH, FSH, PRL kits through NIAMDD. We appreciate the careful technical assistance of Miss K. Ichinoseki.

\section{References}

1) Alger, M., Vazquez-Matute, L., Mason, M., Canales, E.S. \& Zárate, A. (1980) Polycystic ovarian disease associated with hyperprolactinemia and defective metoclopramide response. Fertil. Steril., 34, 70-71.

2) Barraclough, C.A. (1961) Production of anovulatory, sterile rats by single injections of testosterone propionate. Endocrinology, 68, 62-67.

3) Black, J.B. \& Mahesh, V.B. (1969) Effect of dehydroepiandrosterone (DHA) on pituitary gonadotropins on ovulation in the rat. Fed. Proc., 28, 506. (abstract)

4) Bradbury, J.T. (1941) Permanent after effects following masculinization of the infantile female rat. Endocrinology, 28, 101-106.

5) Duignan, N.M. (1976) Polycystic ovarian disease. Brit. J. Obstet. Gynec., 83, 593-602.

6) Fukushima, M., Suzuki, M. \& Maki, M. (1980) Basic research on the mechanism of ovarian hyperstimulation syndrome. Jap. J. Fertil. Steril., 25, 343. (Japanese)

7) Gorski, R.A. (1963) Modification of ovulatory mechanisms by postnatal administration of estrogen to the rat. Amer. J. Physiol., 205, 842-844.

8) Greene, R.R. \& Burrill, M.W. (1941) Postnatal treatment of rats with sex hormones: the permanent effects on the ovary. Amer. J. Physiol. Soc., 133, 302-303. (abstract)

9) Halász, B. \& Pupp, L. (1965) Hormone secretion of the anterior pipuitary gland after physical interruption of all nervous pathways to the hypophysiotrophic area. Endocrinology, 77, 553-562.

10) Holt, J.A., Richards, J.S., Midgley, A.R., Jr. \& Reichert, L.E., Jr. (1976) Effect of prolactin on LH receptor in rat luteal cells. Endocrinology, 98, 1005-1013.

11) Huang, W.Y.\& Pearlman, W.H. (1962) The corpus luteum and steroid hormone formation. I. Studies on luteinized rat ovarian tissue in vitro. J. biol. Chem., 237, 10601065 .

12) Judd, H.L., Rigg, L.A., Anderson, D.C. \& Yen, S.S.C. (1976) The effects of ovarian wedge resection on circulating gonadotropin and ovarian steroid levels in patients with polycystic ovary syndrome. J. clin. Endocr., 43, 347-355.

13) Kanbegawa, A. (1975) Estrogen. Saishin-Igaku, 30, 790-798. (Japanese)

14) Katz, M., Carr, P.J., Cohen, B.M. \& Millar, R.P. (1978) Hormonal effects of wedge resection of polycystic ovaries. Obstet. Gynec., 51, 437-444.

15) Knudsen, J.F., Costoff, A. \& Mahesh, V.B. (1975) Dehydroepiandrosterone-induced polycystic ovaries and acyclicity in the rat. Fertil. Steril., 26, 807-817.

16) Maric, D.K., Matsuyama, E. \& Lloyd, C.W. (1965) Gonadotropin content of pituitaries of rats in constant estrus induced by continuous illumination. Endocrinology, 77, 529-536.

17) Mazer, M. \& Mazer, C. (1939) The effect of prolonged testosterone propionate administration on the immature and adult female rat. Endocrinology, 24, 175-181.

18) Nikitovitch-Winer, M.B. (1965) Effect of hypophysical stalk transection on luteotropic hormone secretion in the rat. Endocrinology, 77, 658-666.

19) Odell, W.D. \& Swerdloff, R.S. (1976) Etiologies of sexual maturation: A model system based on the sexually maturing rat. Recent Prog. Horm. Res., 32, 245-288.

20) Ota, H., Fukushima, M., Ichinoseki, K. \& Suzuki, M. (1979) Prolactin secretion in polycystic ovary syndrome. Acta obstet. gynec. jap., 31, 2032. (abstract) 
21) Quigley, M.E., Rakoff, J.S. \& Yen, S.S.C. (1981) Increased luteinizing hormone sensitivity to dopamine inhibition in polycystic ovary syndrome. J. clin. Endocr., 52, 231-234.

22) Rajaniemi, H.J., Rönnberg, L., Kauppila, A., Ylöstalo, P. \& Vihko, R. (1980) Luteinizing hormone receptors in ovarian follicles of patients with polycystic ovarian disease. J. clin. Endocr., 51, 1054-1057.

23) Saito, A.E. \& Fukushima, M. (1969) Changes in daily urinary excretion of folliclestimulating and luteinizing hormones caused by ethinyl-estradiol and conjugated equine estrogens (Premarin) in low doses. Tohoku J. exp. Med., 97, 119-139.

24) Shay, H., Gershon-Cohen, J. \& Paschkis, K.E. (1939) The effect of large doses of testosterone propionate on the female genital tract of the very young rat. Production of ovarian cysts. Endocrinology, 25, 933-943.

25) Thorner, M.O. (1977). Prolactin. Clin. Endocr., 6, 201-222.

26) Valkov, I.M. \& Dokumov, S.I. (1977) Effect of ovarian wedge resection for the Stein-Leventhal syndrome on plasma FSH, LH, oestradiol and testosterone levels and on the responses of the pituitary to intravenous LHRH. Brit. J. Obstet. Gynec., 84, 539-542.

27) Ward, R.C., Costoff, A. \& Mahesh, V.B. (1978) The induction of polycystic ovaries in mature cycling rats by the administration of dehydroepiandrosterone. (DHA) Biol. Reproduct., 18, 614-623.

28) Wortsman, J. \& Hirschowitz, J. (1980) Galactorrhea and hyperprolactinemia during treatment of polycystic ovary syndrome. Obstet. Gynec., 55, 460-463. 